\title{
Modeling The Nuclear Fuel Cycle
}

\section{International System Dynamics Conference}

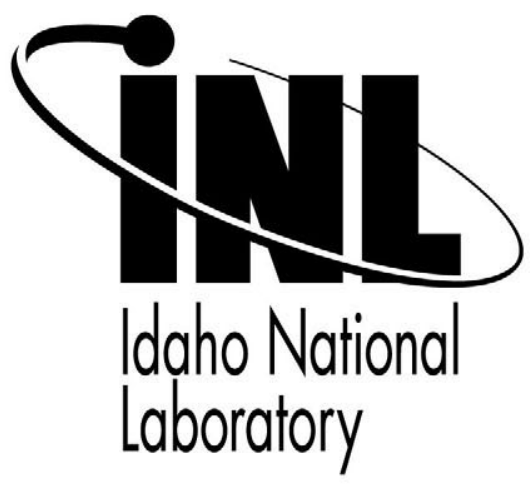

\author{
A.M. Yacout \\ J.J. Jacobson \\ G.E. Matthern \\ S.J. Piet \\ A. Moisseytsev
}

July 2005

This is a preprint of a paper intended for publication in a journal or proceedings. Since changes may not be made before publication, this preprint should not be cited or reproduced without permission of the author. This document was prepared as an account of work sponsored by an agency of the United States Government. Neither the United States Government nor any agency thereof, or any of their employees, makes any warranty, expressed or implied, or assumes any legal liability or responsibility for any third party's use, or the results of such use, of any information, apparatus, product or process disclosed in this report, or represents that its use by such third party would not infringe privately owned rights. The views expressed in this paper are not necessarily those of the United States Government or the sponsoring agency. 


\title{
Modeling the Nuclear Fuel Cycle
}

\author{
A.M. Yacout ${ }^{1}$, J. J. Jacobson ${ }^{2}$, G. E. Matthern ${ }^{2}$, S. J. Piet ${ }^{2}$ and A. Moisseytsev ${ }^{1}$ \\ 1 Argonne National Laboratory, 9700 S. Cass Avenue \\ Argonne, IL 60439 \\ ${ }^{2}$ Idaho National Laboratory, 2525 N. Fremont Avenue \\ Idaho Falls, Idaho 83415
}

\begin{abstract}
The Advanced Fuel Cycle Initiative is developing a system dynamics model as part of their broad systems analysis of future nuclear energy in the United States. The model will be used to analyze and compare various proposed development scenarios. The model will also give a better understanding of the linkages between the various components of the nuclear fuel cycle that includes uranium resources, reactor number and mix, nuclear fuel type and waste management. Each of these components is tightly connected to the nuclear fuel cycle but is usually analyzed in isolation of the other parts. This model will attempt to bridge these components into a single model for analysis. This work is part of a multi-national laboratory work between Argonne National Laboratory, Idaho National Laboratory, Sandia National Laboratory and United States Department of Energy. This paper summarizes the basics of the system dynamics model and looks at some results from the model.
\end{abstract}

Keywords: System Dynamics, Nuclear Fuel Cycle, Systems Analysis

\section{Introduction}

The nuclear fuel cycle represents a complex system with different components and activities that are combined to provide nuclear energy to a variety of end users. The end uses of nuclear energy include electricity, process heat, water desalination, district heating, and possibly future hydrogen production. The fuel cycle system analysis has been for a while part of the development of the peaceful applications of nuclear energy and part of the global studies of energy systems [1]. Recently, the standard system dynamics tools, such as VenSIM [2], iThinK [3], and PowerSim [4], has become a familiar fuel cycle system analysis tools to investigate issues related to its dynamics on both local and global levels.

Different levels of system dynamics involvement in the nuclear fuel cycle analysis have been considered. The early activities in this area were related to the Nuclear Strategy Project at 
Science Applications International Corp. (SAIC) [5-8] which used simple system dynamics models to foster an improved technical dialog between policymakers and expert groups in different areas of interest. Following those simple system dynamic models, complicated models were developed which considered more details of the fuel cycle and the interplay between the different components of the cycle [9-12]. Within those models, different levels of system sophistication were considered. The DYMOND model [10], developed for the Generation IV (Gen-IV) [11] Fuel Cycle Cross Cut group (FCCG) system studies provided a detailed system dynamics model for the global nuclear enterprise with different fuel cycle technologies. The code tracked the mass flow of nuclear materials within the fuel cycle and included different types of delays and feedbacks associated with the construction of nuclear facilities and the decisions to build such facilities. Although economics calculations were part of the code development, however, decisions based on economic estimates were not considered. A step further in simulating the complexity of the fuel cycle was provided through the DANESS model [12], which expanded the different fuel cycle technologies and nuclear fuel types, in addition to allowing for decisions based on economic, experience, environmental, and governmental policy feedback. The two models have been used extensively in complicated fuel cycle deployment scenarios for both the international and the US nuclear enterprise [11-18].

The work presented here is focused on the modeling of the future nuclear fuel cycle developments in the US as part of the Department of Energy (DOE) Advanced Fuel Cycle Initiative (AFCI) program [19]. The paper describes the DYMOND fuel cycle system dynamics model and associated delays and possible feedbacks, and the interplay between the different parts of the system, in addition to preliminary model results.

\section{Advanced Fuel Cycle Initiative}

The United States Department of Energy (US-DOE) has initiated a program to assess the capabilities of nuclear power to support the growing need for energy and energy security in the US. The AFCI's fundamental objective is to provide technology options that - if implemented would enable long-term growth of nuclear power while improving sustainability and energy security. 
Nuclear energy's growth, and thereby its contribution to improving sustainability and energy security, can be enhanced by technology development aimed at the key challenge areas of long term waste management, nuclear fuel utilization, energy production flexibility and economics. Thus, AFCI technology development focuses on reducing the long-term environmental burden of nuclear waste, enhancing the use of nuclear fuel resources, and integrating multiple reactor and fuel types. Each of these three objectives have elements that support and conflict with the other objectives. There is no single "optimum" solution; rather there are regions of preferred operation which depend on time and a range of technical and societal factors (e.g. economics and waste storage regulations).

A key step in identifying the regions of preferred operation was the development of a version of the DYMOND $[10,11,16]$ system dynamic model, DYMOND-US, to capture the structure of the system and help determine the key components and identify any fundamental tipping points (events that cause collapse or un-sustainable growth). DYMOND-US is being used to develop a better understanding of the linkages between the various components in the system and how the system will react to change. The results of the model are being used to guide research and development efforts and to provide decision makers with a transparent tool for considering multiple strategies for nuclear power development.

Some of the questions the model is helping to answer include the following:

- What alternatives exist to building multiple geologic repositories while still supporting an expanding role for nuclear energy?

- How can the principles of reduce, reuse, and recycle best be applied to nuclear power development?

- What types of reactors and fuels will be needed and when will they be needed to minimize long term waste management, while maintaining economic competitiveness?

- What elements of the nuclear fuel cycle are most sensitive to changes in economics, waste policy, energy supply options, and development of new technologies? How do we make the system flexible, robust, and dependable? 
The broad systems analysis, which DYMOND-US supports, is a collaborative effort between the Idaho National Laboratory (INL), Argonne National Laboratory (ANL), and US-DOE Nuclear Energy Office. This broad system analysis is using a set of analysis models that represents a complete integrated nuclear energy operating system which covers the life-cycle of the nuclear fuel cycle activities. Those activities include uranium mining and enrichment, fuel fabrication, reactor irradiation, spent fuel storage, fuel recycling, partitioned storage, transportation, packaging, long-term storage, and final waste emplacement at a repository. DYMOND-US shows composite fuel flows through the system that represent the overall volumes, capacities, and flows across the nuclear energy complex.

\section{DYMOND-US Model}

The DYMOND-US model provides simplified representations of actual fuel material flows from fabrication, reactor irradiation, spent fuel storage, fuel recycling and partitioned storage, transportation, packaging, and final disposition in long-term storage and at a repository. The model helps address the questions of recycling options, reactor mix and timing, nuclear fuel options and waste management options. The overall goal is to help evaluate the mix of reactors, fuel reprocessing and fabrication, and waste management facility capabilities required and timing of their implementation for a sustainable nuclear fuel system in the US.

The model includes the following system elements:

Mining \& Enrichment

- Current natural uranium stocks (U.S. and international)

- Uranium enrichment facilities (for either enriching natural uranium ore or in some scenarios enriching recycled uranium)

Fuel Fabrication

- Current US stock of enriched uranium fuel

- Fabrication of fuel that uses transuranics from reprocessed spent fuel 
Reactor Park

- Current 103 U.S. operating reactors (types, design life)

- Reactor Life-time extension status (relicensing)

- Reactor specifications for next generations options,(types, e.g., Very High Temperature Reactors producing hydrogen, and fast reactors)

- Deployment schedules for new reactors (of either current type or new types)

Reactor Operations

- Burn-up rates for fuel, power output, fuel usage

- Reactor refueling intervals and reactor lifetime

- Reactor Thermal efficiency

Spent Nuclear Fuel Storage

- Mass and composition of Spent Nuclear Fuel inventories

- Spent fuel generation rates

- Reactor on-site storage capacity (wet and dry)

Recycling and Reuse of Spent Nuclear Fuel

- Elemental and isotopic separation parameters and efficiencies

- Single and multi recycle strategies

- Fresh fuel compositions utilizing recycled radionuclides

- Element based stream disposition (recycle, transmutation, low level waste disposal, long-term storage)

- Elemental and isotopic level mass balances and flows

Additional Storage Requirements

- Storage capabilities and limitations for short-lived fission products (Cs, $\mathrm{Sr}$ )

- Storage capabilities and limitations for long-lived fission products(I, Tc)

- Storage capabilities and limitations for transuranics (plutonium, americium, neptunium, and curium) and uranium

- Current recycle inventories 
- Low-level waste storage

Waste Packaging and Transportation

- Waste package characteristics

- Transportation capabilities (mass/volume capacities, heat loading, packaging)

- Interstate shipment requirements

Repository Disposal

- Repository capabilities (mass/volume capacities, heat loading, radiotoxicity, separated zones)

Not included within the system definition at present

- Facility, site or location specific data

- Waste management treatment processes (High Level Waste treatment)

- Environmental Remediation or Decontamination \& Disposal wastes

- International resources or potential interfaces

The DYMOND-US model is organized into a series of interconnected sectors. Each sector focuses on a particular sector of the overall system. Two of the sectors are discussed here: the Reactor Park sector which tracks the addition and subtraction of nuclear reactors to the national operating fleet and the Fuel Cycle sector which tracks the lifecycle of the fuel, from initial fabrication to placement into long-term storage. There is also a short discussion on the model interface used in DYMOND-US.

\subsection{Reactor Park Sector}

The Reactor Park Sector tracks the life cycle of reactors. The structure uses an array structure to track the different types of reactors, current Light Water Reactors, and several next generation nuclear power plants (with varying types of coolants - sodium, lead, molten salt, or helium). Reactors will be ordered at a rate dependent on a demand function, and possibly other criteria such as materials inventories or other economic factors (economic decision making is not 
currently implemented in the model). Once a reactor is ordered it has to be licensed, built, operated and retired. The basic structure is shown in Figure 1.

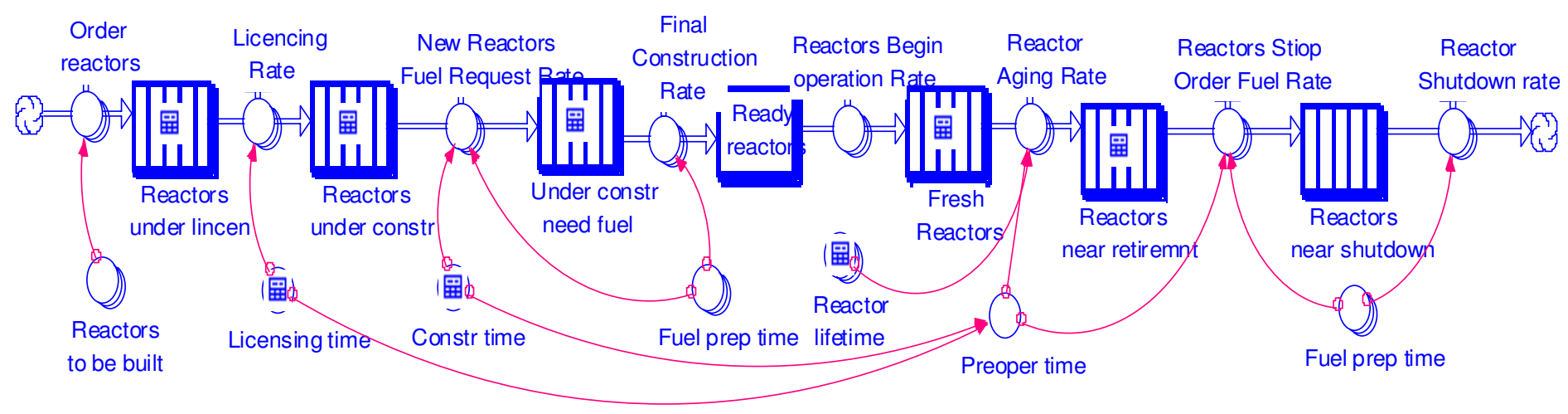

Figure 1: Reactor Life-Cycle Model

The reactors are tracked through the different stages of development that are represented by stocks (accumulations) in the form of conveyors that contain the reactors in each stage. The stock regulators (flows) represent transfer from one stage to another. Every conveyor is governed by a specific time characteristic (delay). For example, the time delay for "Reactors under construction" is "Construction time", which is the time it takes to build a reactor.

The decision to order a new reactor is the driving force for that sector. To determine how many new reactors to order we need to compare demand with deployed reactors plus reactors being licensed and reactors under construction. In addition, since licensing and construction of a new reactor takes time (Licensing time + construction time $=$ pre-operation time) some of the "Operating Reactors" will retire during this time. Therefore, we need to compare demand against only operating reactors that are "far from retirement". "Far from retirement" means reactors that will not retire during "Pre-operation time". This is done by dividing operating reactors into two groups, "Fresh reactors" and "Reactors near retirement". The conveyor time 
for "Fresh Reactors" is "Reactor lifetime" minus "Pre-operation time"; the conveyor time for "Reactors near retirement" is "Pre-operation time".

In addition, "under construction need fuel" and "Reactors near shutdown" are two reactor states that are related to fuel supply. Since fuel fabrication takes time (enrichment time + fabrication time), fuel supply to a new reactor will be ordered ahead of time so it will be available for reactor startup. "Reactors near shutdown" does not need new fuel as it is close to shutdown after "Fuel preparation time", i.e. "Enrichment time" + "Fuel fabrication time", and fuel should have been already available for those reactors.

The previous reactor structure is for new reactors. A second structure was developed to track legacy reactors, that is, existing reactors that have already been built, and have been operating for different periods of time. This secondary structure tracks the operation and retirement of all legacy reactors. Legacy reactors will be retired based on a retirement schedule which can be approximated as follows. The starting number of reactors is 103 reactors where each reactor generates $950 \mathrm{MWe}$. The reactors are scheduled to retire starting the year 2027 and retire at a linear rate until all are retired by the year 2043. The structure is very similar to the previous structure without the construction stages (Figure 2).

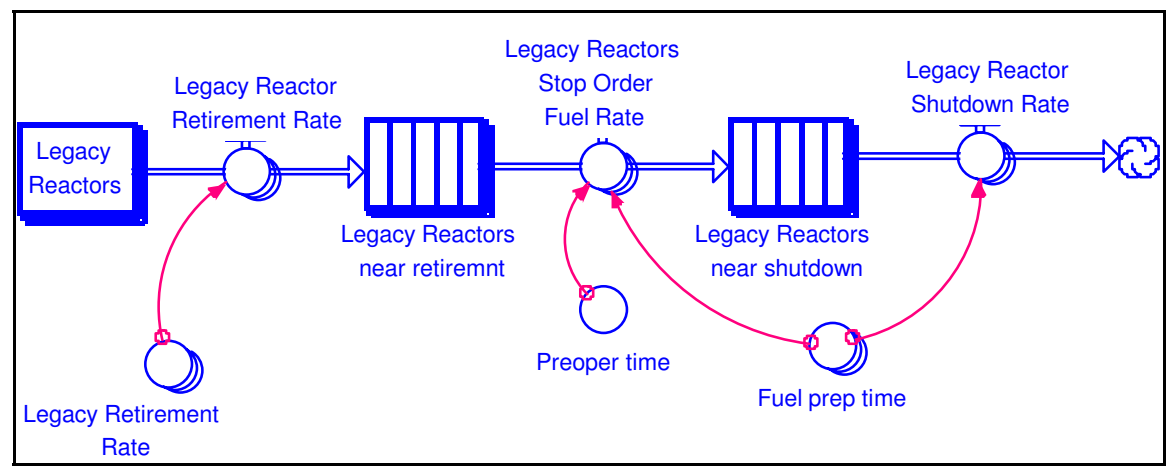

Figure 2: Existing LWRs Model 


\subsection{The Fuel Cycle Sector}

The fuel cycle model tracks the life-cycle of the nuclear fuel. Considering the oncethrough fuel cycle (no fuel reprocessing): there are six stages modeled; mining, enrichment, fuel fabrication, irradiation in reactor, short-term spent fuel storage, and long-term geological storage (Figure 3), where there is a delay between each stage (not shown in the figure).

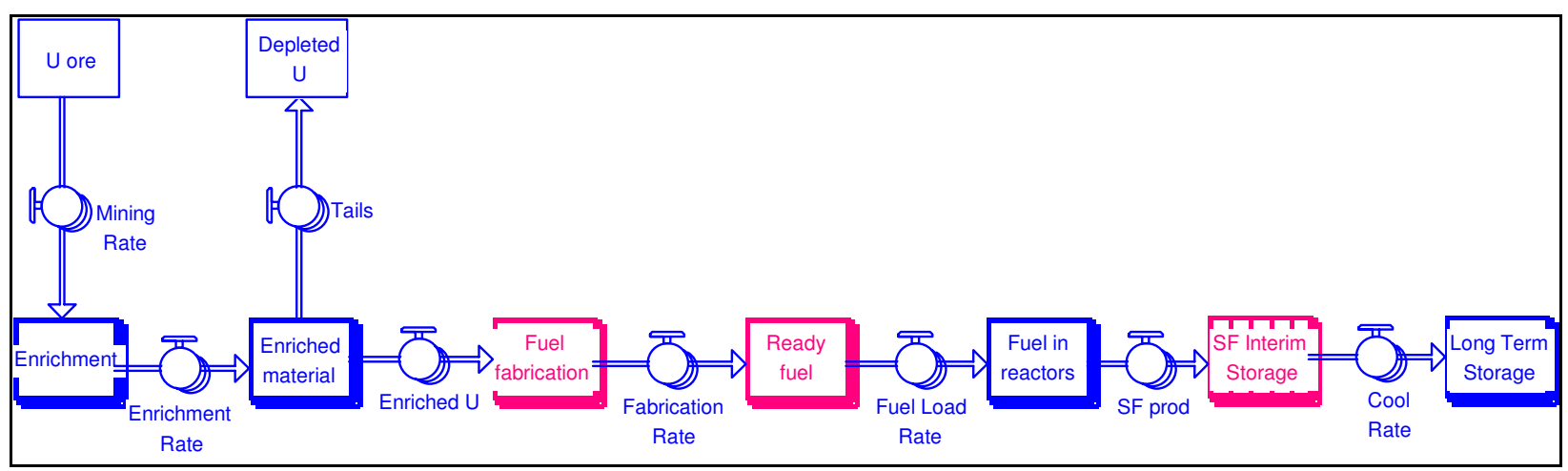

Figure 3: Once-Through Fuel Cycle

Mined uranium ore goes to enrichment plants where part of this material is converted into enriched uranium and the remaining part becomes depleted uranium. Enriched uranium goes to the fuel fabrication plant, "Fuel fabrication". A new reactor will not start if there is not enough fuel to load the reactor. Therefore, we need to know how much fresh fuel is produced and ready for loading into reactors, "Ready fuel". Once fuel is loaded into the reactor, it spends a specific time in-reactor after which it is removed from the reactor as spent fuel. This fuel, because of its heat load, must be stored locally at the reactor in wet storage for several years, "SF Interim Storage". After the spent fuel has cooled sufficiently to allow handling and transportation, the fuel can be sent to a long-term waste repository, "Long Term Storage".

The above structure models the "Once-through" fuel cycle. Fuel is used once in a reactor and then shipped to long-term storage. Another option being considered is to reprocess spent fuel and recover the usable material (actinides such as $\mathrm{Pu}, \mathrm{Np}, \mathrm{Am}, \mathrm{Cm}$ ) that is still abundant in the spent fuel. The recovered material can then be reused as fuel for reactors. This would decrease 
the need for mining new uranium ore. Reprocessing could also decrease the required amount of long-term repository storage.

Figure 4 shows a simple flow of the closed fuel cycle (the current version of the model contains a much more complex system with different options for the closed fuel cycle) with the added structure needed to include reprocessing. Reprocessed material can be split into recovered uranium, plutonium, minor actinides $(\mathrm{MA}=\mathrm{Np}, \mathrm{Am}, \mathrm{Cm})$ and high-level waste (HLW). The plutonium can be used in new fuel fabrication for mixed oxide fuels (MOX). If other types of fuel are developed then the other components can also be incorporated.

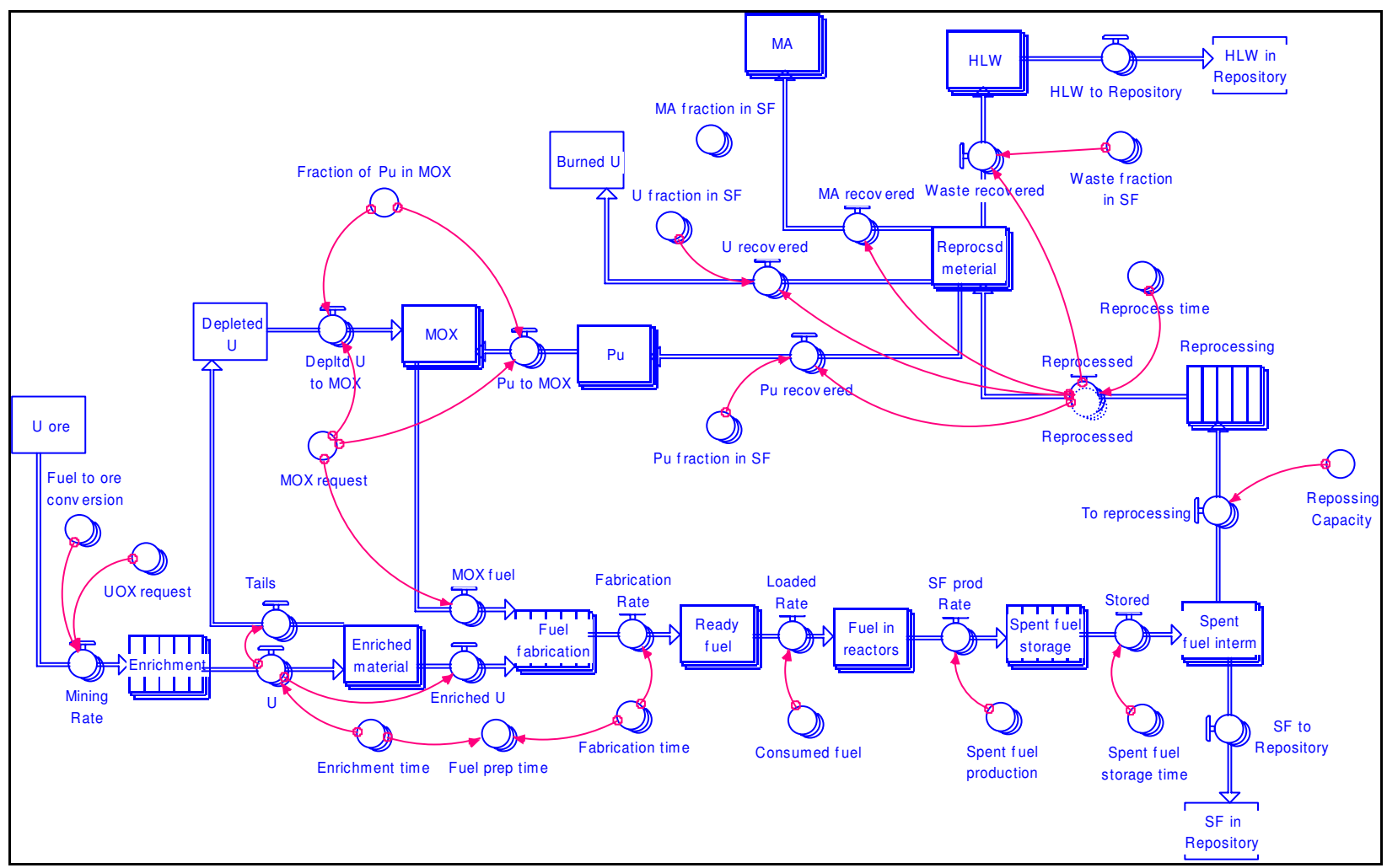

Figure 4: This Figure Shows a Simplified Version of the Complete Fuel Cycle Structure when Including Recycling.

\subsection{Model Interface}

The current model was developed using Stella/Ithink Version 8.0 development tool [2]. The model is a set of difference equations that can be solved through numerical integration 
according to several techniques available in Stella, such as Euler's method or a second order or fourth order Runge-Kutta method. Stella has a very powerful set of tools for developing a user interface. Figure 5 shows the interface "Home" page. The user can maneuver around the model from this page by clicking on the button of the section that the user wants to view. Base case simulations based on current parameters can be performed easily. There are a series of 8 scenarios that have been pre-defined. These are described in more detail in the next section. The user can select a particular scenario by clicking on the appropriate radio button. Additional simulations based on management and design criteria can be tested against the base cases. The interface includes stereo control buttons for starting and stopping a simulation.

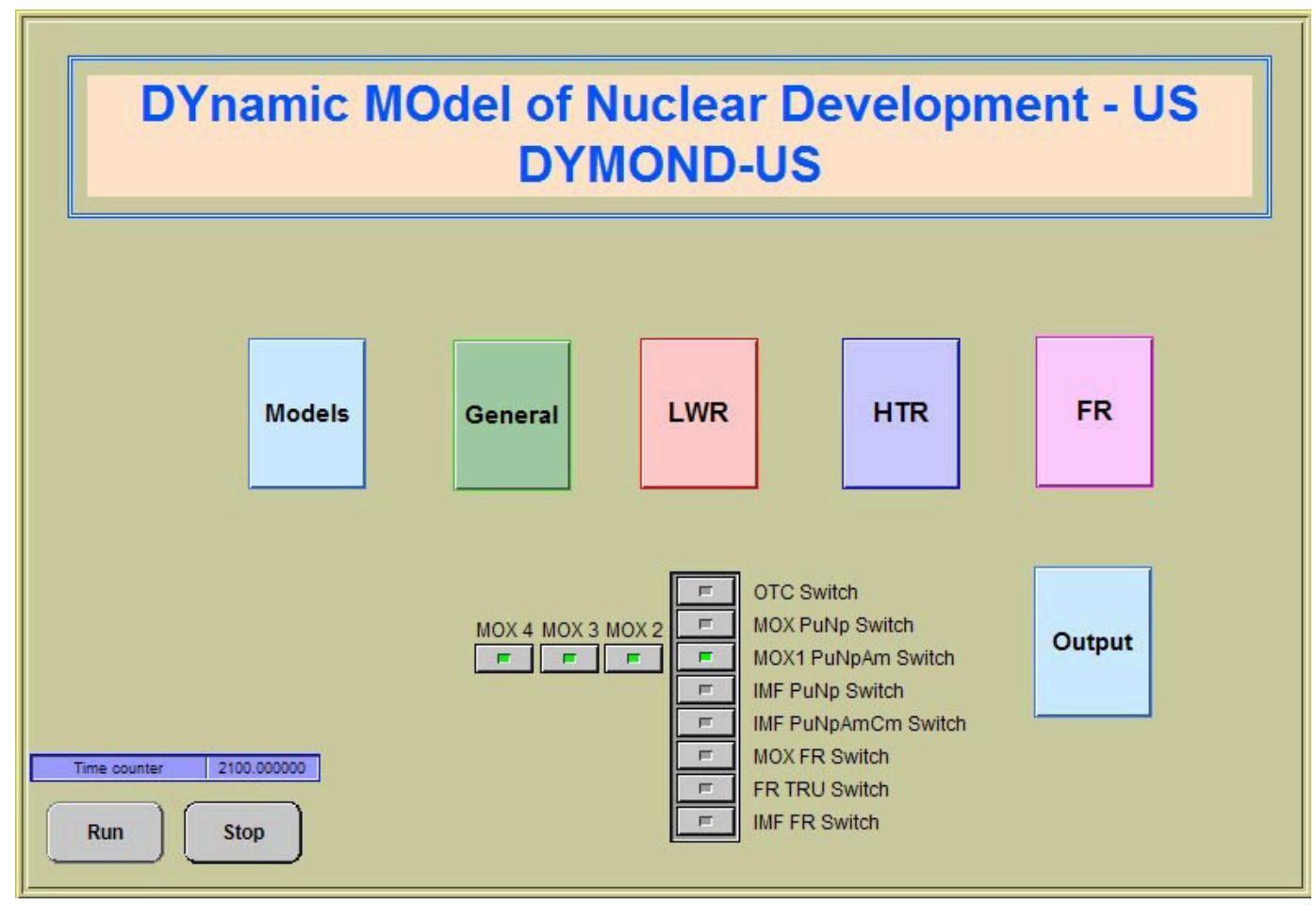

Figure 5: Model Main Page

In addition, there are parameter panels for modifying the general parameters, as well as parameters for each reactor type. Figure 6 shows the parameter panel for general information. The user can change parameters by editing the values in the tables, by clicking on or off the radio buttons or by moving the slider button in the slider boxes. If a value has been changed then a $U$ button appears in the parameter box that the user can click on to reset the value to its original value. The interface is designed around a point and click environment which minimizes typing 
from the user. There are panels for adjusting parameters for each type of reactor, LWR, FBR, VHTR and LWR MOX.

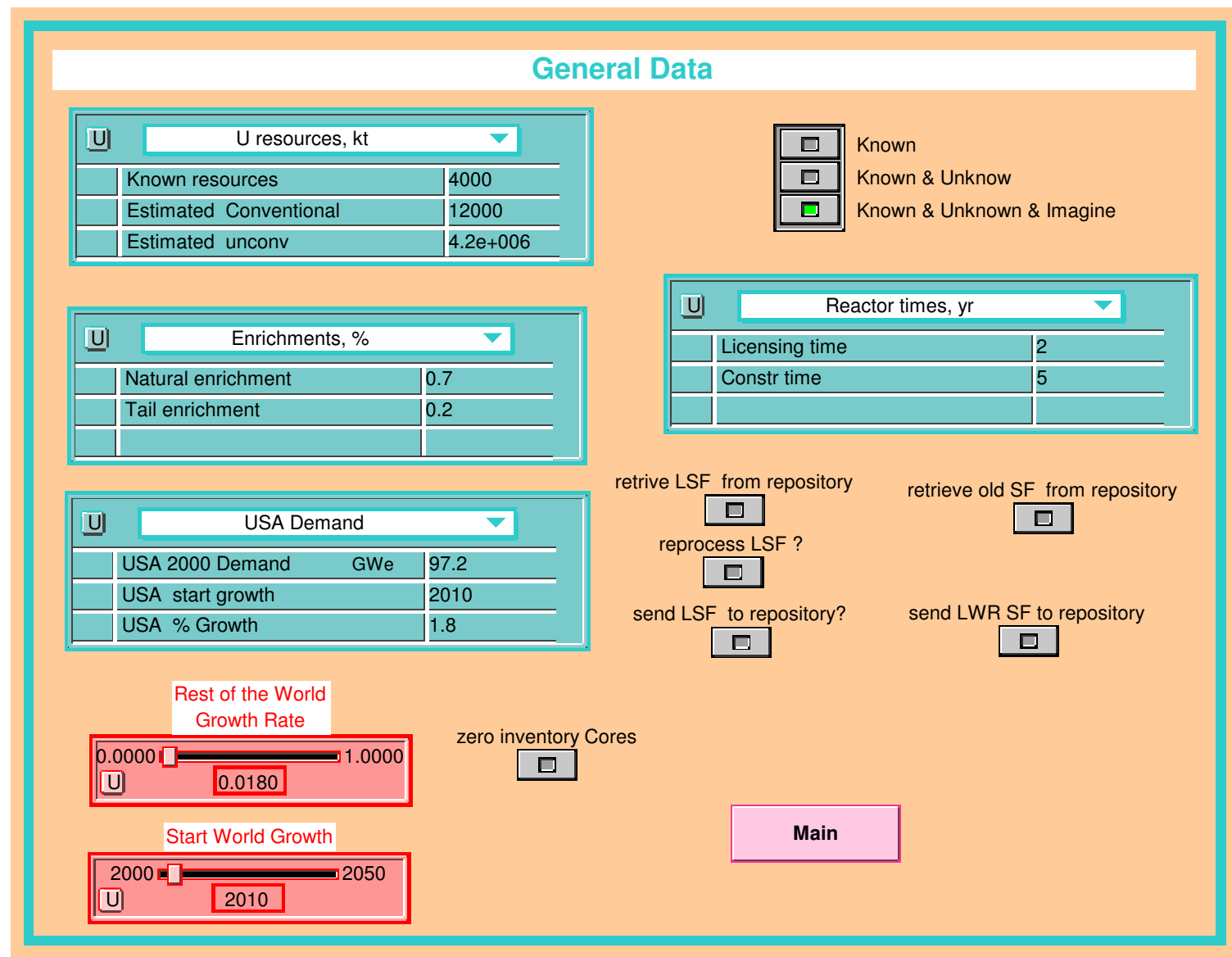

Figure 6: Interface for Changing General Model Parameters.

\subsection{Strategies}

The model is being designed to answer the questions posed by policy makers related to strategies for future deployment of nuclear reactors in the US. To do so, it is helpful to consider four possible strategies. Here, a strategy is a general approach to fuel cycle management that encompasses a range of options with similar basic characteristics. Typically, a strategy identifies which materials are recycled (if any), the type of nuclear power plant, the type of spent fuel processing technology, and which materials go to geologic disposal. 
The current U.S. strategy is once through - all the components of spent fuel are kept together and eventually sent to a geologic repository (Figure 7). The second strategy is limited recycle, where transuranic elements (e.g., $\mathrm{Pu}, \mathrm{Np}, \mathrm{Am}, \mathrm{Cm}$ ) are recycled once (Figure 8). Residual transuranic elements and the long-lived fission products would go to geologic disposal. Uranium in spent fuel, depleted uranium, and short-lived fission products would be disposed as low-level waste. This strategy emphasizes use of existing infrastructure and existing technology, especially current and near-term types of thermal reactors.

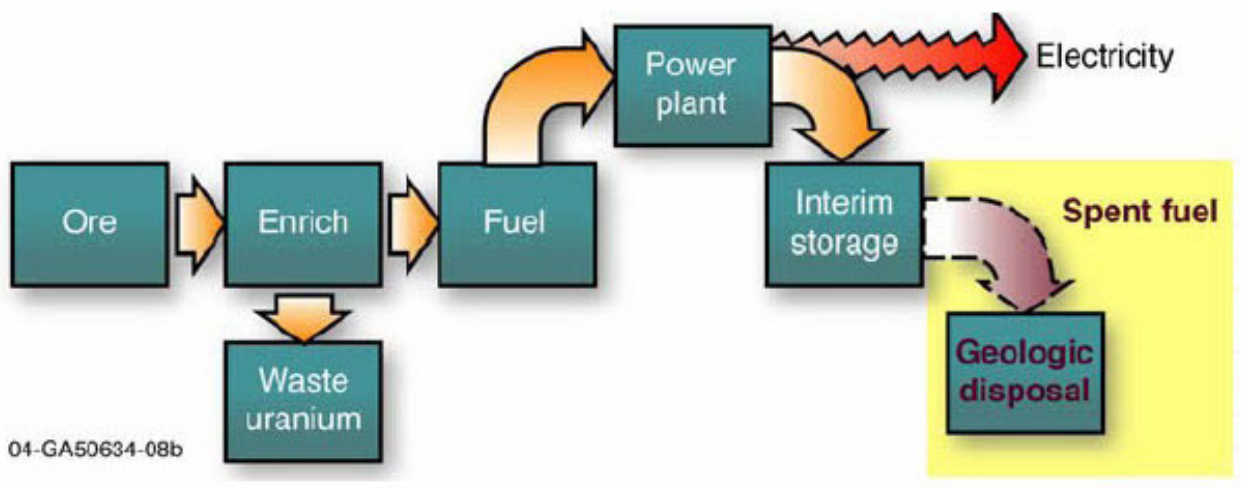

Figure 7: Once-Through Strategy

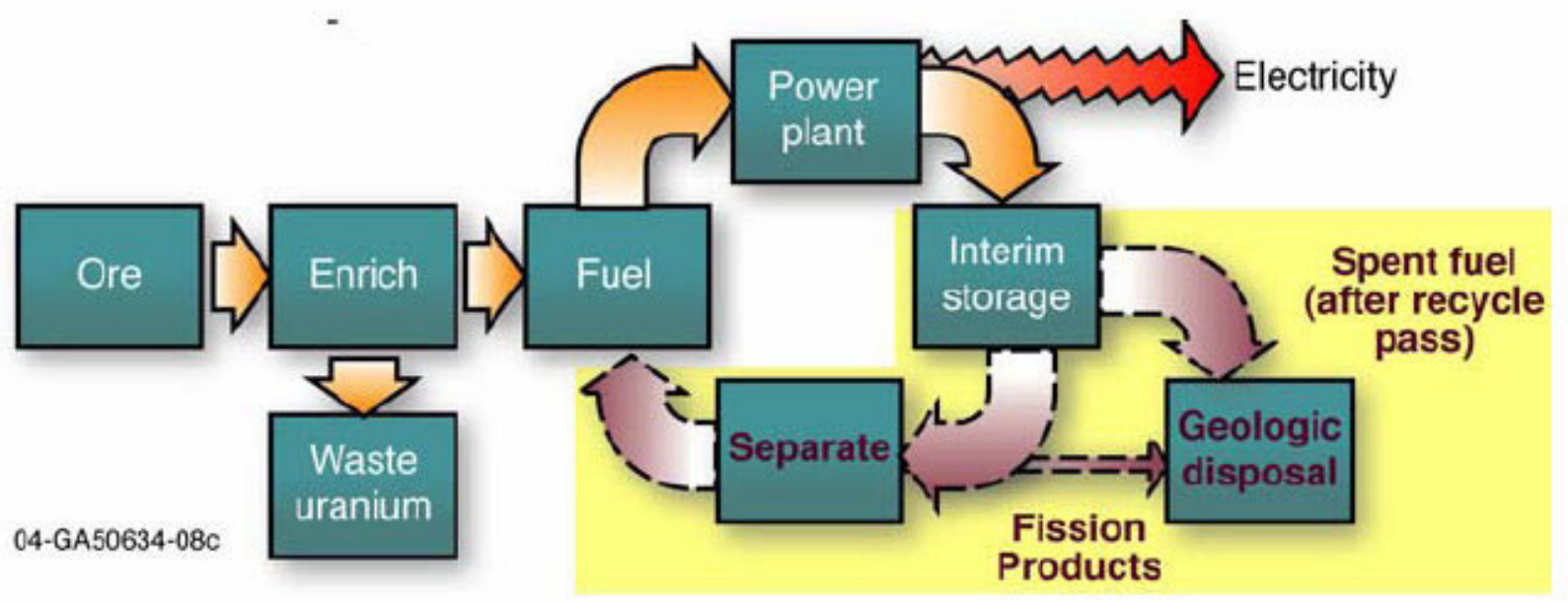

Figure 8: Limited Recycle Strategy 
The third strategy is continuous recycle, recycling transuranic elements from spent fuel repeatedly (Figure 9). Sustained recycle is more technically challenging than limited recycle and therefore additional $R \& D$ and technology deployments would be required. Uranium in spent fuel can be recycled or disposed. Essentially no transuranic elements would go to geologic disposal. Long-lived fission products would either go to geologic disposal or some could be transmuted in power plants. Short-lived fission products would be disposed as low-level waste or sent to temporary storage. This strategy would primarily use thermal reactors; however, a small fraction of fast reactors may be required.

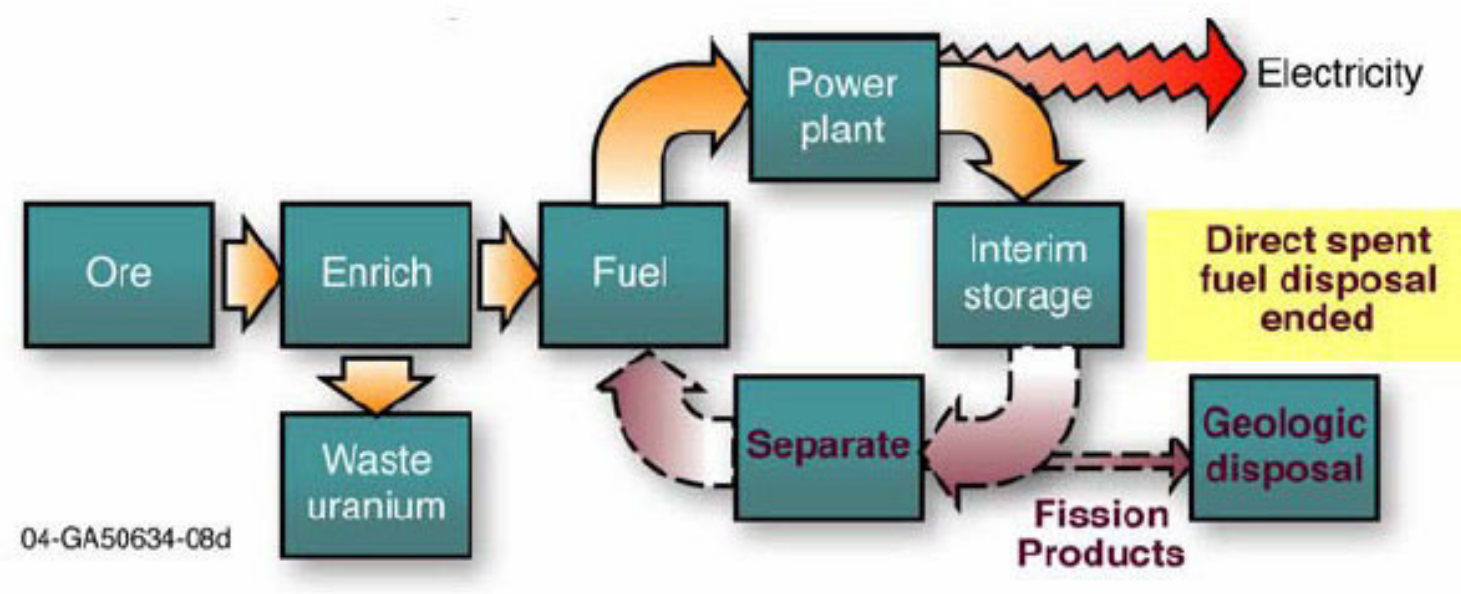

Figure 9: Continuous Recycle Strategy

The fourth strategy is sustained recycle, which differs from continuous recycle primarily by enabling the recycle of depleted uranium to significantly extent fuel resources. This strategy would primarily use fast reactors. 


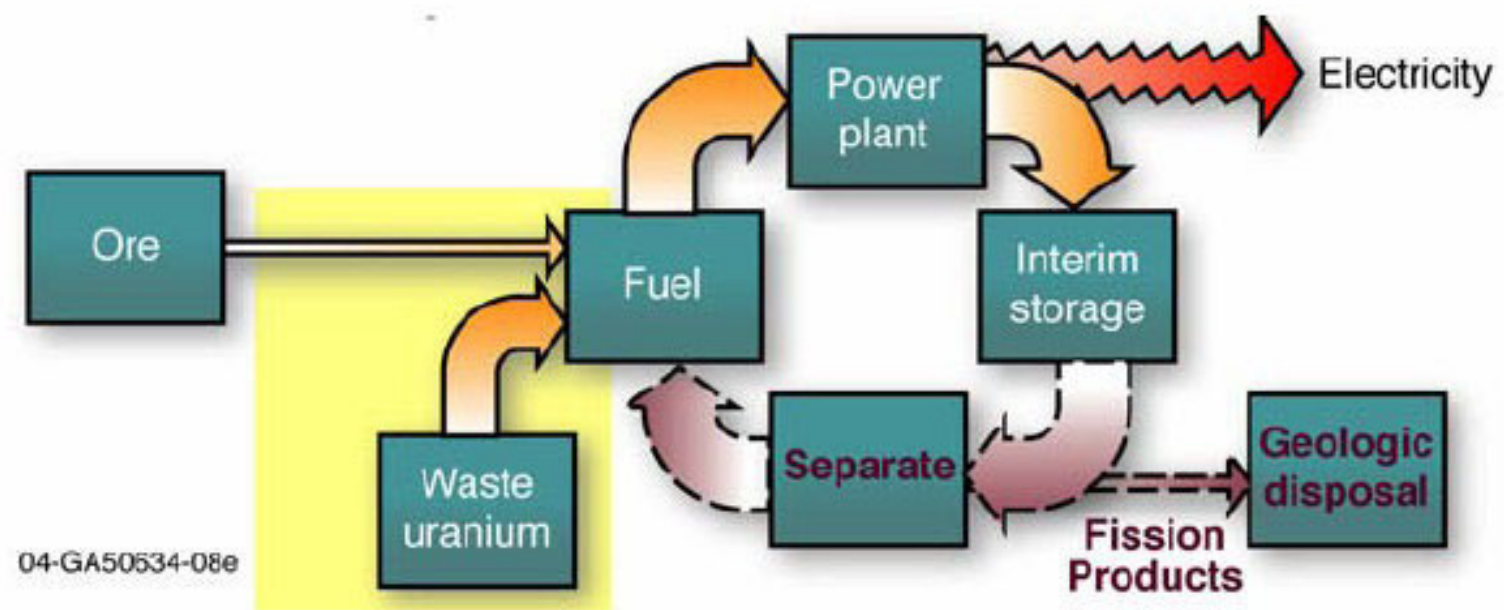

Figure 10: Sustainable Recycle Strategy

Notice that each of these four strategies can be addressed through the different scenario options that are provided in the model starting page, Figure 5.

\subsection{Sample Scenarios Results}

Running the model has produced several interesting results. Looking at available uranium resources with several best guesses on uranium availability shows uranium resources could run out before 2100 for the once-through strategy and a 3.2\% growth in nuclear power. This is based on the assumption of high estimate of remaining uranium resources of 12 million tons where only the US is using the resource. In other words, for an aggressive nuclear power growth, uranium resources will be expended by the end of the century with the once-through strategy. It should be noted that additional sources could be discovered if there were an economical driver for further exploration. 


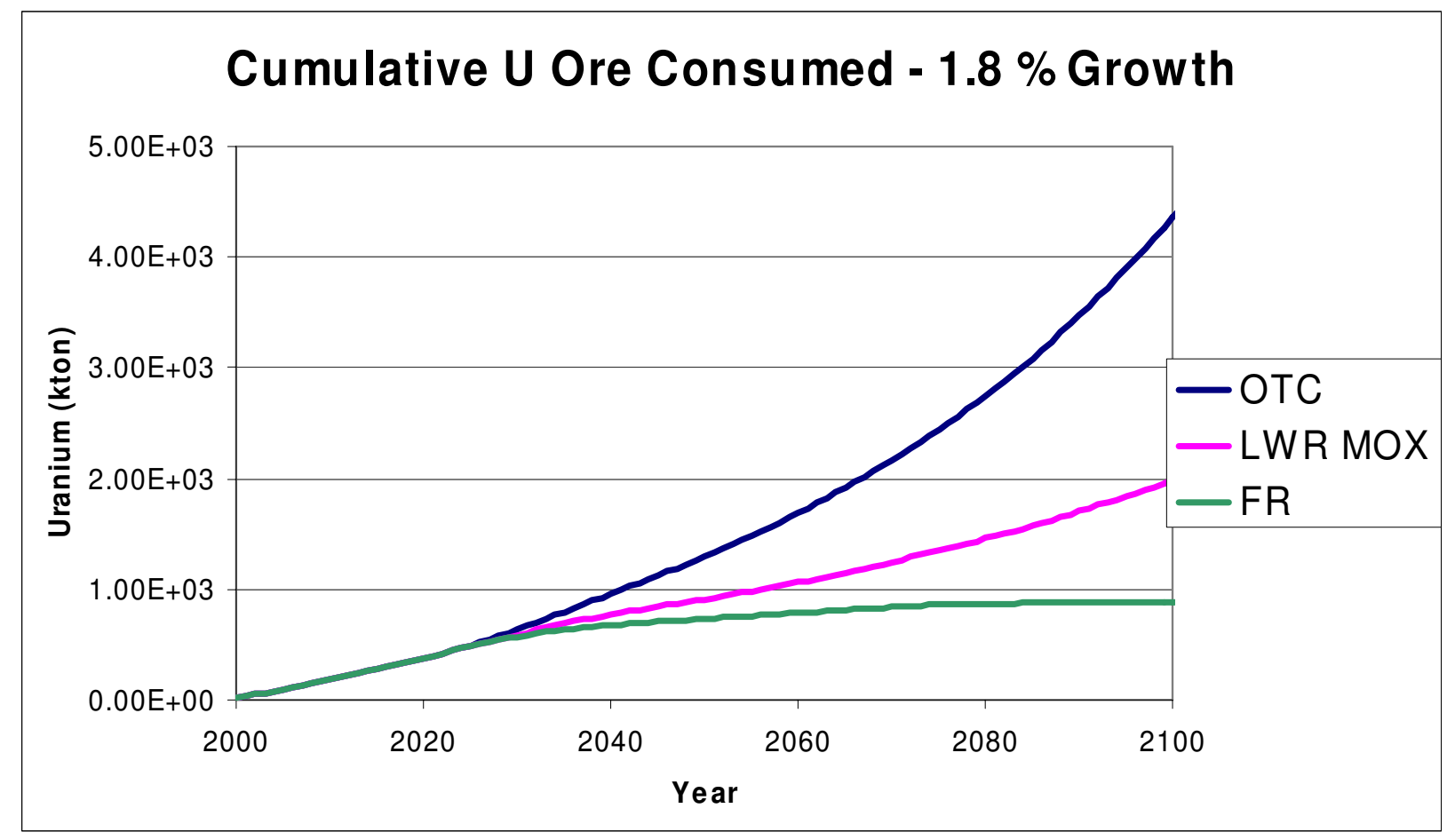

Figure 11: Comparison of the Amount of Uranium Ore Consumed under Three Different Strategies, where the Assumed Growth Rate for Energy Demand is 1.8\%.

The first comparison examines the amount of uranium ore consumed by different scenarios (Figure 11). The first scenario is the "Once-through" (OTC) with no reprocessing. The second scenario is LWR reactors using MOX fuels (LWR MOX; fuel that contains some or all the transuranics from reprocessed spent fuel). The final scenario utilizes Fast Reactors (FR) with continuous reprocessing. The comparison shows that the once-through strategy will require much more uranium resources than either of the two other options. This option might be acceptable as long as we are not pushing the world limits of available uranium ore; otherwise, one of the other scenarios becomes more favorable.

The next figure shows the same three scenarios given a higher energy demand growth rate of $3.4 \%$. The once-through scenario requires close to 3 times as much uranium ore as from the once-through $1.8 \%$ growth case. It also requires nearly 3 times as much uranium ore as in the LWR MOX case. 


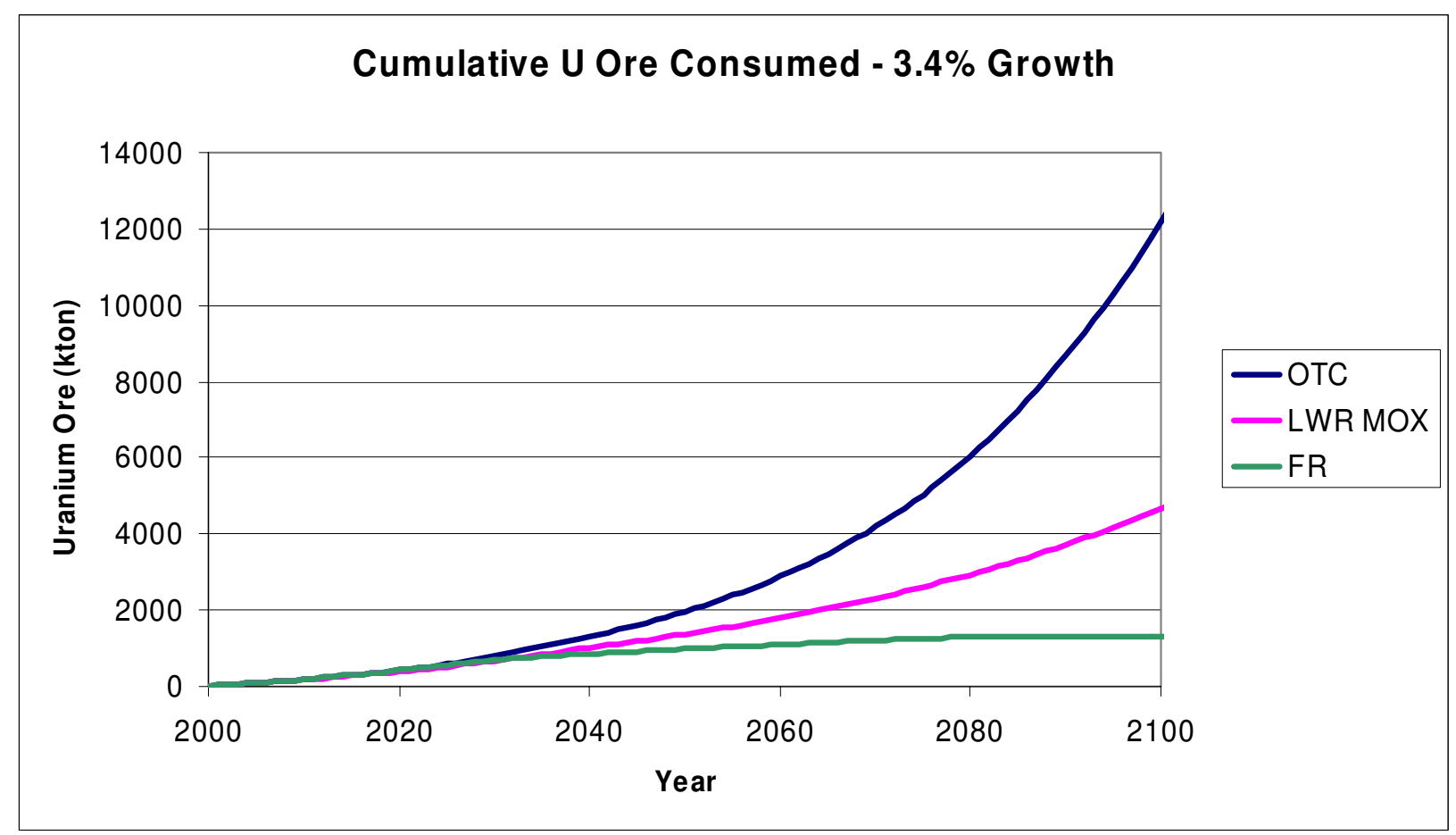

Figure 12: The Amount of Uranium Ore Required to Meet the Demand for Three Different Strategies for $3.4 \%$ Demand Growth Rate

Another example of the model capabilities is shown in Figure 13, which shows the accumulations of plutonium associated with the different nuclear deployment strategies. The figure includes the once-through strategy for two types of fuel (high and low burnup fuel), in addition to the limited and continuous recycling strategies. The comparative plutonium accumulations provided by the model can guide the policy maker on the future deployment strategy if that type of accumulations is an important decision making factor. 


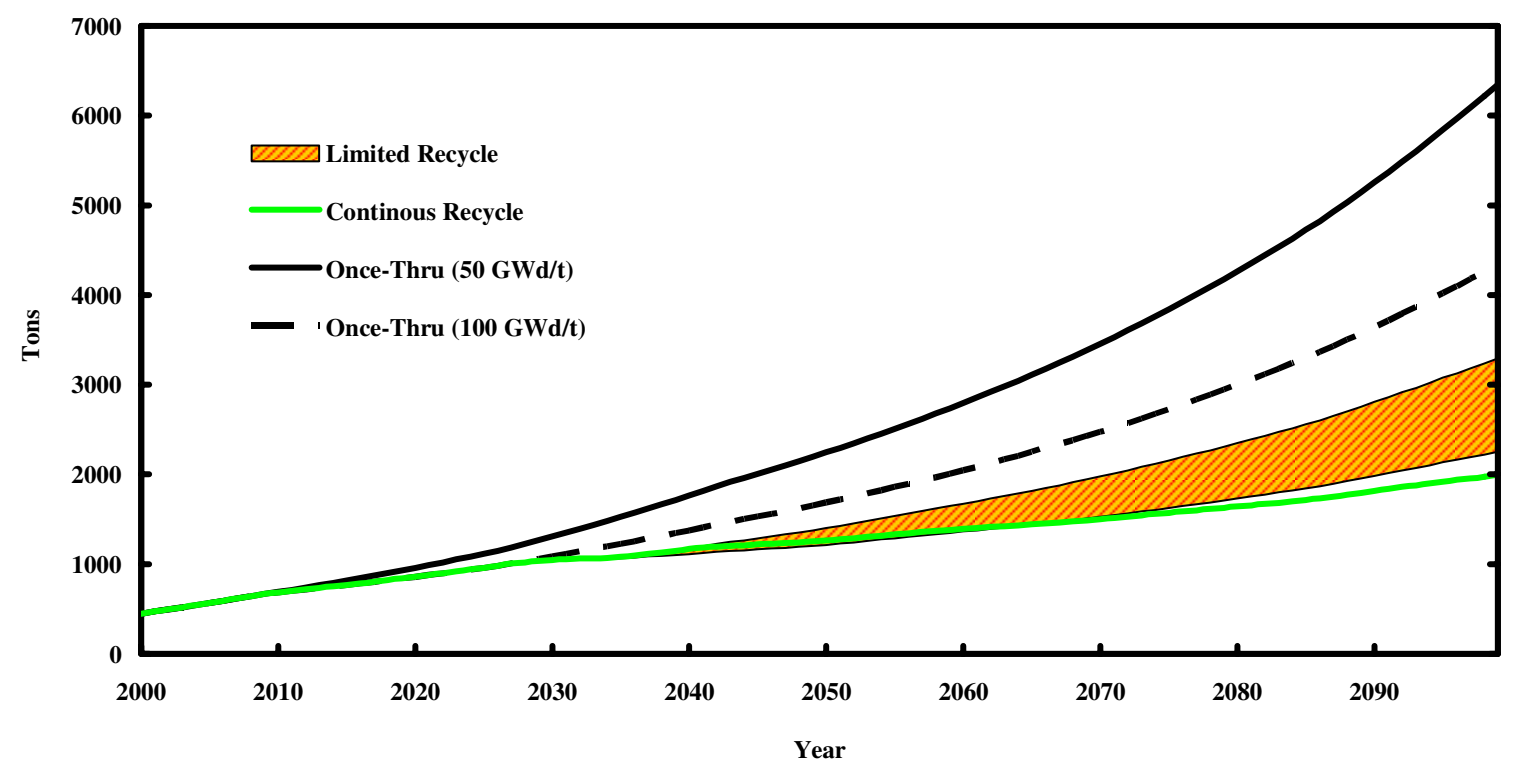

Figure 13: Comparison between the Plutonium Accumulations in the Nuclear Fuel Cycle for Different Deployment Strategies

\subsection{Summary}

The system dynamics model presented here has the potential of allowing decision makers and stakeholders to explore long-term behavior and performance of the complex nuclear energy systems, especially in the context of dynamic processes and changing nuclear deployment scenarios. The model is currently used in the context of deployment scenarios associated with the US-DOE Advanced Fuel Cycle Initiative. It has already provided valuable insight into the future consequences of different deployment strategies and it will continue to do so with the incorporation of more capabilities into the model.

\section{Acknowledgements}

This work was performed under the auspices of the DOE under contract W-31-19-Eng-38. 


\section{References:}

1. W. Hafele, "Energy in a Finite World, a Global Systems Analysis," International Institute for Applied Systems Analysis (IIASA), Ballinger Publishing Company, Cambridge, MA, 1981.

2. ITHINK Software, ISEE Systems, Inc.

3. Vensim, Ventana Systems, Inc., http://www.vensim.com.

4. PowerSim, Powersim Software, http://www.powersim.com.

5. V. Reis, "Nuclear Strategy Project," SAIC, 1998.

6. R. E. Ellis, "The Use of System Dynamics to Model the System Impacts of the Russian Brest Reactor Design,” SAIC Report to DOE and ANL, January 2001.

7. Nuclear Strategies Project Workshop on the Disposition of Excess Weapons Plutonium in Russia, DTRA and SAIC, Washington D.C., April 2001.

8. A. M. Yacout, "Disposition of Russian Excess Plutonium," Nuclear Strategies Project Workshop, Argonne National Laboratory, December 2001.

9. Y. Guan, "Systemic Analysis, Mapping, Modeling, and Simulation Applied to the Advanced Accelerator Applications Program,” ASTM, Inc., Report to DOE and ANL, May 2001.

10. A. Moisseytsev. "DYMOND, a Dynamic Model of Nuclear Development," Argonne National Laboratory Internal Report, August, 2001.

11. US-Department of Energy, "A Technology Roadmap for Generation IV Nuclear Energy Systems," GIF-002-00, Dec. 2002.

12. L. Van Den Durpel, A. Yacout, D. Wade, H. Khalil, "DANESS, Dynamic Analysis of Nuclear System Strategies," in GLOBAL 2003 Meeting, November 16-20, 2003, New Orleans, LA, USA.

13. L. A. Malczynski, et. al., "Regional Dynamic Simulation Modeling and Analysis of Integrated Energy Futures," Sandia National Laboratory Report SAND2002-3737, November 2001.

14. V. H. Reis, M. P. Crozat, A Strategy for Nuclear Power: The Role of Government. San Diego, Calif. : SAIC, June 2002. Power Choice Model 
15. L. Van Den Durpel, D. C. Wade, H. Khalil, A. Yacout, "Dynamic Analysis of Nuclear Energy System Strategies for Electricity and Hydrogen Production in the USA," in GLOBAL 2003 Meeting, November 16-20, 2003, New Orleans, LA, USA.

16. A. M. Yacout, R. N. Hill, L. Van Den Durpel, P. J. Finck, E. A. Schneider, C. G. Bathke and J. S. Herring, "Dynamic Analysis of the AFCI Scenarios," PHYSOR 2004, Chicago, Illinois, April 25-29, 2004.

17. A. M. Yacout, L. Van Den Durpel, D. C. Wade, and H. Khalil, "Scenarios for the Expanded Use of Nuclear Energy," 2004 International Congress on Advances in Nuclear Power Plant (ICAPP '04), Pittsburgh, PA USA, June 13-17, 2004.

18. C. J. Jeong, H. Choi, and A. M. Yacout, "A Sensitivity Analysis for the Environmental Effect of the DUPIC Fuel Cycle," ANS Annual Meeting, Pittsburg, PA; June 13-17, 2004.

19. US-DOE, Report to Congress on Advanced Fuel Cycle Initiative: The Future Path for Advanced Spent Fuel Treatment and Transmutation Research, January 2003. 